Mosquera, D., B. Fessl, D. Anchundia, E. Heyer, C. Leuba, E. Nemeth, M. L. Rojas, C. Sevilla, and S. Tebbich. 2022. The invasive parasitic fly Philornis downsi is threatening Little Vermilion Flycatchers on the Galápagos Islands. Avian Conservation and Ecology 17(1):6. https://doi. org/10.5751/ACE-02040-170106

Copyright (C) 2022 by the author(s). Published here under license by the Resilience Alliance.

Research Paper

\title{
The invasive parasitic fly Philornis downsi is threatening Little Vermilion Flycatchers on the Galápagos Islands
}

\author{
Denis Mosquera ${ }^{1,2}$, Birgit Fessl $^{1}$ (D) , David Anchundia ${ }^{1,2}$, Eileen Heyer ${ }^{1,2}$, Celina Leuba ${ }^{1,2}$, Erwin Nemeth $^{3}$, Maria Lorena Rojas ${ }^{1}$, \\ Christian Sevilla ${ }^{4}$ and Sabine Tebbich ${ }^{2}$ \\ ${ }^{1}$ Charles Darwin Research Station, Charles Darwin Foundation, Santa Cruz, Galápagos Islands, Ecuador, ${ }^{2}$ Department of \\ Behavioural and Cognitive Biology, University of Vienna, Austria, ${ }^{3}$ BirdLife Austria, ${ }^{4}$ Galápagos National Park Directorate, \\ Galápagos Islands, Ecuador
}

\begin{abstract}
Populations of several species of birds endemic to the Galápagos Islands have declined during recent decades, including endemic Little Vermilion Flycatchers (Pyrocephalus nanus). Understanding the reasons for the low breeding success of this species is a prerequisite for developing efficient conservation strategies. Studies of sympatric Darwin's finches suggest two potential reasons: parasitism by the invasive parasitic fly Philornis downsi and extreme climatic events. We investigated the role of each in the breeding success of Little Vermilion Flycatchers during three breeding seasons in the agricultural zone of Isabela Island. We found that Little Vermilion Flycatchers were severely affected by $P$. downsi, depending on the time of breeding. Nest success was high early in the breeding season $(60 \%$ were successful) when rates of $P$. downsi prevalence and intensity were low, but nest success was zero and all nests were infested later in the breeding season. Philornis downsi prevalence and intensity increased with increasing temperature. Both low and high levels of rainfall had a negative effect on nest survival. A parasite removal experiment using insecticide confirmed the detrimental effect of the invasive parasite; nests infested with $P$. downsi had significantly lower nest success than treated nests. Injection of insecticide into nest bases can be an efficient short-term way to increase the nesting success of Little Vermilion Flycatchers, but finding long-term measures to control the $P$. downsi population is of utmost importance.
\end{abstract}

\section{La mouche vampire aviaire Philornis downsi menace la moucherolle des Galápagos}

RÉSUMÉ. Les populations de plusieurs espèces d'oiseaux endémiques des îles Galápagos ont décliné depuis quelques décennies, y compris celle des moucherolles des Galápagos (Pyrocephalus nanus). Il est essentiel de comprendre les raisons du faible taux de reproduction de cette espèce pour développer des stratégies de conservation efficaces. Des études menées sur les pinsons de Darwin sympatriques suggèrent deux raisons possibles : le parasitisme lié à la mouche vampire aviaire Philornis downsi et les événements climatiques extrêmes. Nous avons enquêté sur le rôle de chaque succès de reproduction des moucherolles des Galápagos au cours de trois saisons de reproduction dans la zone agricole de l'île d'Isabela. Nous avons constaté que les moucherolles des Galápagos étaient très affectées par la $P$. downsi, selon le moment de la période de reproduction. Le succès des nids était élevé au début de la saison de reproduction ( $60 \%$ d'entre eux réussissaient) lorsque la prévalence et l'intensité des taux de P. downsi étaient faibles, alors que le succès des nids était nul et que tous les nids étaient infestés plus tard au cours de la saison de reproduction. La prévalence et l'intensité des populations de Philornis downsi augmentait avec la hausse des températures. Les niveaux de pluviosité faibles ou élevés entraînaient des effets négatifs sur la survie des nids. Une expérience d'élimination des parasites à l'aide d'insecticide a confirmé les effets délétères des parasites invasifs ; les nids infestés de $P$. downsi présentaient un taux de succès des nids nettement inférieur par rapport aux nids traités. L'injection d'insecticide dans les bases des nids peut constituer un moyen efficace à court terme pour augmenter le succès de la nidification des moucherolles des Galápagos, mais il est indispensable de trouver des mesures à long terme pour contrôler la population de P. downsi.

Key Words: alien species; breeding ecology; conservation; decline; experimental; host-parasite interactions; nest

\section{INTRODUCTION}

Nearly all oceanic archipelagos lost part of their original avifauna following human colonization (Steadman 1995, 2006, Blackburn et al. 2004). The Galápagos islands are a notable exception and are known as one of the most intact refuges for native avifauna in the world (Jiménez-Uzcátegui et al. 2019). However, this may change because several populations, including those of some endemic species of Darwin's finches, are declining (Grant et al. 2005, Dvorak et al. 2012, 2020, Dvorak et al. 2017, Fessl et al.
2017). Populations of two species of Vermilion Flycatchers (Pyrocephalus spp.) have also declined over the past 30 years on at least three inhabited islands (Merlen 2013). Previously considered as two subspecies of the continental Vermilion Flycatcher (Pyrocephalus rubinus), they have now been recognized as two separate endemic species (Carmi et al. 2016). The Least Vermilion Flycatcher (Pyrocephalus dubius), restricted to San Cristóbal Island, is the first extinction of a Galápagos bird in modern history (BirdLife International 2017), though evidence 
gained by interviewing locals suggests that a small population may have persisted until very recently (Dvorak et al. 2020). The Little Vermilion Flycatcher (Pyrocephalus nanus) inhabits the other major islands with the exception of Genovesa and Española (Fessl et al. 2017) and has been recently classified as vulnerable by the International Union for the Conservation of Nature (IUCN; BirdLife International 2017). This species has already been extirpated on Floreana Island (Merlen 2013, Dvorak et al. 2017) and is now estimated to number only 30 to 40 breeding pairs on Santa Cruz Island (Fessl et al. 2017).

Reasons for the declining populations of the two species of Galápagos Vermilion Flycatchers are unknown, but studies of sympatric Darwin's finches suggest several possible explanations including egg predation by rodents associated to high nest failure rates $(>50 \%)$ in the endangered Mangrove Finch (Camarhynchus heliobates; Fessl et al. 2010), reduced food abundance or accessibility by habitat change caused by invasive plants (Dvorak et al. 2012, Cimadom et al. 2014), and extreme rainfall negatively affecting nest success (Cimadom et al. 2014). Furthermore, previous studies have revealed a clear relationship between declining populations of species of Darwin's finches and the presence of the avian vampire fly Philornis downsi (Kleindorfer and Dudaniec 2016, Fessl et al. 2018, McNew and Clayton 2018). This fly is an obligatory bird parasite during its larval stage (Fessl et al. 2006a). Its presence in bird nests in the Galápagos was first noted in 1997 (Fessl and Tebbich 2002), but entomological records document the first fly record from 1964 (Causton et al. 2006). The flies lay eggs in bird nests either during incubation or posthatching. Most first instar larvae develop in the nares of nestlings, and second instar larvae then move to the nest base where they suck blood from nestlings, leading to a reduction in hemoglobin concentration, decreased mass gain in young hosts, and ultimately increased nestling mortality (reviewed in Fessl et al. 2018). Experimental reduction of $P$. downsi numbers in nests of Darwin's finches resulted in higher breeding success for several species (Fessl et al. 2006b, Koop et al. 2013, Cimadom et al. 2019). Philornis downsi particularly negatively affects bird species with small body size (Dudaniec et al. 2007) and small clutch size (Kleindorfer and Dudaniec 2016, Fessl et al. 2018). The Little Vermilion Flycatcher exhibits both these conditions; therefore, we suspect that the avian vampire fly could be one of the major causes for the rapid decline of this species.

Weather and habitat quality may also influence the breeding success of Little Vermilion Flycatchers. Nestlings of Green Warbler-Finches (Certhidea olivacea) and Small Tree-Finches (Camarhynchus parvulus), both land birds that co-occur with Little Vermilion Flycatchers, had reduced nestling survival when they experienced days with heavy rain (Cimadom et al. 2014). Cimadom et al. (2014) hypothesized that heavy rain events could lead to reduced parental feeding rates. However, seasonal and associated climatic parameters could also influence the prevalence and intensity of $P$. downsi and explain a decline in reproductive success under more humid conditions. We aimed to determine (1) the effects of habitat, season, rainfall and temperature, and nest predation on the breeding success of the Little Vermilion Flycatcher, (2) the effects of season and climatic variables on $P$. downsi prevalence and intensity in Little Vermilion Flycatcher nests, and (3) the effects of $P$. downsi parasitism on Little Vermilion Flycatcher nestling survival with an experimental approach.

\section{METHODS}

Our study was conducted in an area of $8 \mathrm{~km}^{2}$ in the humid zone of Isabela Island in the highlands of the Sierra Negra volcano around El Cura (050'4.88" S, 91 '5'25.44" W, 550-1000 m above sea level; Appendix 1, Fig. A1.1), which maintains an estimated population of 150 Little Vermilion Flycatcher breeding pairs. Our study site included both managed and abandoned farmland and an area of guava forest that is part of the Galápagos National Park. The guava tree (Psidium guajava) is an invasive plant threatening several island ecosystems (Cronk and Fuller 1995). Active farmland comprises guava forest mixed with pasture for cattle. Farmers keep the pasture open by manual control and by fumigating the regrowth with herbicides to kill the young guava trees. Abandoned farmland comprises dense guava stands and less pasture. Farmland borders are marked by large trees, predominantly Ecuadorian Walnut or Nogal(Juglansneotropica), and other introduced plant species.

\section{Study species}

Little Vermilion Flycatchers are found in open and semi-open areas and are sit-and-wait insectivores, foraging close to the ground using low perches (Leuba et al. 2020). They are nonmigratory and endemic to the Galápagos Islands. Nests of Little Vermilion Flycatchers are small, open-cup nests, placed on branch forks or on thick branches (Harris 1974). The nest is built mainly by the female, and both male and female provide food for the nestlings (D. Mosquera, personal observation).

\section{Monitoring of reproductive activity}

Data on breeding success were collected during three breeding seasons: 10 November 2014 to 25 May 2015, 4 December 2015 to 4 April 2016, and 9 November 2016 to 25 March 2017. Hereafter, we refer to each breeding season by the year in which it began.

During the first season, 2014, 49 Little Vermilion Flycatchers were captured (12 males, 19 females, and 18 juveniles) using mist nets (6 $x 4 \mathrm{~m}, 2.5-\mathrm{cm}$ mesh) and banded with a unique combination of three colored bands and one numbered metal band. Resightings of marked individuals were recorded during all subsequent field seasons. At the beginning of each field season, breeding territories were identified by the presence of an aggressive male, an aggressive female, a displaying male, a male and a female interacting and/or copulating, an incubating female, or an adult feeding nestlings. All sightings of Little Vermilion Flycatchers and all nests found were marked by GPS waypoints. In case of nest failure, pairs often built new nests nearby. Thus, all nests within the area identified for a marked breeding pair were considered to belong to the same pair.

To avoid pseudo-replication, we randomly chose one nest per breeding pair per season for analysis and excluded a total of 37 nests over the three study years. Numbers of second nest attempts were too small to treat nest as a random factor. Nesting attempts between years were treated as independent. We excluded seven nests that were treated for a parasite exclusion experiment. The remaining sample consisted of 110 nests, with 50 monitored in 2014, 30 in 2015, and 30 in 2016.

Nests were checked at five-day intervals during nest building, every three days during incubation, and every two days during the nestling period. When nestlings were close to fledging, nests were checked daily (see Cimadom et al. 2014). We determined 
onset of breeding, clutch size, date of hatching, number of nestlings, and date of failure or fledging, either by direct observation or by inspecting nests with an endoscopic camera (model dnt, Findoo 3.6). After each visit, observers waited until one of the adults returned to the nest to verify the nest was still active.

Successful nests were defined as nests that produced at least one fledgling observed outside of the nest at least once. Failed nests were categorized as (1) abandoned (only eggs in the nest), (2) empty during incubation (nest previously containing eggs found empty), (3) empty during the nestling stage (nest previously containing young found empty, nestlings $\leq 10$ days), (4) dead nestlings, (5) predated (destroyed or partially destroyed nest, or empty nest during feeding when the nestlings were older than 11 days and no fledgling was found around the nest), or (6) other (e.g., nest tree fell or nest fell for unknown reasons). Categories 2 and 3 could be caused by either nest predation or $P$. downsi parasitism, i.e., just hatched chicks and nestlings died during the period between two visits and were removed by parents (D. Mosquera, personal observation).

The duration of incubation period was calculated as the number of days from the date of clutch completion to the day the first egg hatched ( $N=29$ nests). The duration of nestling period was calculated by counting the number of days between the day the first egg hatched and the last day parents were observed feeding nestlings in successful nests $(N=16)$. The incubation period, nestling period, and date when first eggs were laid were used to estimate the date of incubation start, a continuous variable used in the general linear models (GLMs). For nests abandoned during incubation, the date of the first observation of incubation was assumed to be the date of incubation start. For the two nests where nestlings hatched before the first observation, pictures and videos were used to estimate nestling age and hatching date. Breeding seasons occurred between the end of one year and the beginning of the next year, so we could not use ordinal dates. To standardize the date of incubation start among years, we numbered the days beginning with the day of the first breeding attempt of each breeding season.

\section{Philornis downsi survey}

Once nests either fledged young or failed, they were collected in individual plastic bags, dismantled, and visually inspected for larvae and pupae of $P$. downsi. Parasite prevalence was defined as the presence or absence (yes/no) of $P$. downsi in the nests. Parasite intensity was defined as the number of $P$. downsi per nest (larvae and pupae) in nests with at least one larva.

Parasite intensity and prevalence could only be assessed once nest activity had ceased. Therefore, the level of parasite intensity and prevalence found in the nest was assigned to the nest stage (eggs, dead nestlings, fledged nestlings) at the time of nest collection.

\section{Habitat and climate}

Several environmental variables were recorded on and around the nest site. At the nest site, we recorded nest height, height of nest trees, nest tree species, diameter of the five trees closest to the nest tree, and vegetation density (compound of bushes and tree coverage together). For the latter, we took a picture at a distance of 5-7 m from the nest and visually assigned it to one of five categories, which ranged from 1 being an open area with only one solitary nest tree to 5 being a nest tree in a closed forest where natural light hardly touches the ground. Within $10 \mathrm{~m}$ around the nest, we recorded maximum canopy height, average tree height, number of trees, diameter of the five trees closest to the nest tree, and percentage of herb, bush (vegetation between $1 \mathrm{~m}$ and $3 \mathrm{~m}$ in height), and tree coverage (in $20 \%$ increments). Within a $50 \mathrm{~m}$ diameter, we recorded average tree height and estimated vegetation coverage (herbs, bushes, and trees). After inspecting data for correlations (assumed if Pearson correlation coefficient between two vegetation variables was higher than 0.45 ), we selected the following uncorrelated variables: nest height, vegetation density at the nest tree, and vegetation coverage (herb layer at $10 \mathrm{~m}$ diameter) to be included in the analysis.

Average temperature $\left({ }^{\circ} \mathrm{C}\right)$ and average rainfall $\left(\mathrm{mm}\right.$ water $\left./ \mathrm{m}^{2}\right)$ data were provided by Kyoto University from a meteorological station located in the study area ( $0^{\circ} 50^{\prime} 12.37^{\prime}$ S, 91 $\left.{ }^{\circ} 5^{\prime} 25.62^{\prime \prime} \mathrm{W}\right)$. To calculate the average temperature for a given nest, we took the mean temperature for each day a nest was active and divided the sum by the number of those days. For average rainfall, we summed the total rainfall for each day a nest was active and divided by the number of days. Average temperatures for the 2016 season were not available because the temperature sensor at the meteorological station failed.

\section{Parasite reduction experiment}

Data were collected in two breeding seasons, from 20 January to 6 March 2017 (season 2016) and 3 February to 18 April 2018 (season 2018). We treated eight nests in 2016 and 15 in 2018 with a $0.5 \%$ permethrin solution (PermaCap CS, Whitmire Micro-Gen Research Laboratories, Inc., St. Louis, MO), which is known to reduce $P$. downsi numbers in the nests of other host species (Cimadom et al. 2019). We used a syringe with a $5 \mathrm{~cm}$ long metal needle and a cut tip. In 2016, we injected $2.5 \mathrm{ml}$ of the permethrin solution into the nest base where $P$. downsi larvae are known to spend the day. In 2018, we only injected $1.5 \mathrm{ml}$ of the solution (the application of either volume of PermaCap CS was highly effective). Nests used for the experiment needed to fulfill the following conditions: $\geq 12$ days of incubation (in 2016), $\geq 7$ days of incubation (in 2018) or nestlings $\leq 6$ days of age (2016 and 2018), and nest height $<6 \mathrm{~m}$ (injection of higher nests was logistically impossible). Treated nests were also selected based on factors that made a safe injection possible without jeopardizing the nest or the researchers. The main factors were the position of the nest on the branch and whether conditions of the ground below the nests permitted safe positioning of an A-ladder. We collected data on $P$. downsi intensity and nestling success for 22 treated nests. One treated nest was predated and excluded from the analysis. The 27 parasitized nests (control group; 10 nests in 2016 and 17 nests in 2018) were all nests that were found active during the same period of time as treated nests and fulfilled the criteria except nest height and factors relevant for safe injection. Nest height did not differ between treated nests and control group nests.

\section{Statistical analysis}

To test the influence of habitat variables and weather conditions on nestling survival, we analyzed the daily survival rate (DSR) of Little Vermilion Flycatchers with the R package RMark (Laake 2013) in $R$ version 3.6.1 ( $R$ Core Team 2018) as an interface to the software MARK (White and Burnham 1999). We estimated 
Table 1. Model selection results for daily nest survival (S) of Little Vermilion Flycatchers (Pyrocephalus nanus), calculated for 84 nests in 2014, 2015, and 2016.

\begin{tabular}{|c|c|c|c|c|c|}
\hline Model & $\mathrm{K}^{\dagger}$ & $\mathrm{AICc}$ & $\Delta \mathrm{AICc}$ & Mass & Deviance \\
\hline $\mathrm{S} \sim$ day of season + year + nest age + rain + rain $^{2}$ & 6 & 350.88 & 0.00 & $4.93 \mathrm{e}-01$ & 338.82 \\
\hline $\mathrm{S} \sim$ day of season + year + nest age + rain + rain $^{2}+$ vegetation density & 7 & 351.75 & 0.87 & $3.19 \mathrm{e}-01$ & 337.67 \\
\hline $\mathrm{S} \sim$ day of season + year + nest age + rain + rain $^{2}+$ nest height & 7 & 352.90 & 2.02 & $1.80 \mathrm{e}-01$ & 338.81 \\
\hline S day of season + year + nest age & 5 & 360.72 & 9.85 & $3.59 \mathrm{e}-03$ & 350.68 \\
\hline$S \sim$ day of season + year + nest age + vegetation density & 6 & 362.14 & 11.26 & $1.77 \mathrm{e}-03$ & 350.08 \\
\hline $\mathrm{S} \sim$ day of season + year + nest age + nest height & 6 & 362.36 & 11.48 & $1.59 \mathrm{e}-03$ & 350.29 \\
\hline S day of season + year & 4 & 394.28 & 43.41 & $1.85 \mathrm{e}-10$ & 386.25 \\
\hline$S \sim$ day of season & 2 & 396.37 & 45.49 & $6.52 \mathrm{e}-11$ & 392.36 \\
\hline$S \sim 1$ & 1 & 403.11 & 52.23 & $2.26 \mathrm{e}-12$ & 401.10 \\
\hline S year & 3 & 406.89 & 56.01 & $3.39 \mathrm{e}-13$ & 400.87 \\
\hline
\end{tabular}

$\mathrm{K}$ is the number of parameters used.

the probability of a nest surviving the 32-interval nesting period (days) as DSR. We used a hierarchical modeling approach (Dinsmore and Dinsmore 2007) to build models to explain variation in nest survival of Little Vermilion Flycatchers, mainly to keep the model set smaller given the large number of covariates compared to a small number of nests with complete information $(N=84)$. In the first step, we fitted 10 models (including Null model, Table 1) to explain within and between year variation in nest survival. These models included constant survival, linear and quadratic time trends, and year as a factor with three levels (2014, 2015, and 2016). We also chose to combine year effects with the best source of within-season temporal variation (constant, linear, or quadratic) into an additive model. We then added possible differences by adding nest age as a linear trend. Thereafter, we chose the best model so far and combined it with nest-specific covariates singly. These predictors were total rainfall during nesting, nest height (log transformed), herb cover, and vegetation density. We evaluated relationships between predictors with Pearson correlation coefficients. The highest correlation was $r=$ 0.61 between day of season and total rain. All other correlations were below 0.45 , and we kept all variables in the models. If more than one nest-specific covariate was represented in competing models $(\triangle \mathrm{AIC}<2)$, we also combined them in a single model. The variable total rain during the nesting period showed a quadratic relationship and thus we used also a quadratic term for this variable. We used Akaike's Information Criterion (Akaike 1973) adjusted for small sample size (AIC $)$ to evaluate model quality (Burnham and Anderson 2002). The influence of single predictors in the best fitting model is shown by their coefficients and standard errors and by plotting the predicted DSR.

To test the influence of the prevalence or intensity of $P$. downsi on DSR, we added this variable with a reduced sample size of 74 nests (no information was available on ten nests because they had disappeared or were out of reach) to the best model. We used $\mathrm{AIC}_{\mathrm{c}}$ to check whether this variable could contribute to better explanation of DSR but found no better predictions. We also compared the relative effect of day of season on nest success compared to $P$. downsi. If a model with $P$. downsi prevalence or intensity had a lower AIC than the found best model, it would suggest that infestation better predicts nest success than just a date effect. However, both variables connected to $P$. downsi did not contribute to a better prediction of DSR (Appendix 2, Table A2.1), and we omitted it in further analysis and presented all results for the larger data set of 84 nests. Thus, we did not use $P$. downsi intensity as a variable in our models. Instead, we tested for detrimental effects of the parasitic flies with a parasite reduction experiment.

Related to the parasite reduction experiment, we compared nestling survival between parasitized and parasite-reduced nests with a Fisher's exact test. To test whether breeding success is predicted by prevalence and intensity, we performed two separate binomial GLMs with breeding success as response variable.

To test for the effect of temperature and season, we performed GLMs for the dependent variables prevalence (binomial distributed error structure) and intensity (Poisson distributed error structure corrected for overdispersion). The independent variables were date of incubation start (for all three years with year as a co-variable) and temperature (complete temperature data were available for 2014 only). Because the date of incubation start was strongly correlated with temperature $(N=49$, Pearson $r=0.99, P<0.001$ ), we used separate models for analyzing the effects of these two variables. All statistical analyses were carried out using R 3.4.1 (R Core Team 2017).

\section{RESULTS}

\section{Resightings of banded birds}

Resightings of banded adults (12 males, 19 females) within the breeding season confirmed that birds occupied the same territory throughout the entire breeding season (January to April 2015). In 2015, we resighted six banded individuals from 2014 and, in 2016, two individuals from 2014 that were still in the same former territory. We did not find any of the 18 juveniles banded in 2014 .

\section{Breeding activity, hatching, and nestling success}

We recorded active Little Vermilion Flycatcher nests from October to May. During the 2014 season, we observed two peaks in breeding activity, namely November-December and MarchApril. In the other two seasons, we detected only one peak: January-February in 2015, and December-January in 2016 (Fig. 1b). We monitored 110 nests from incubation onward. Clutch size was $2.1 \pm 0.41$ (mean $\pm \mathrm{SD}, N=110)$, the incubation period lasted $15.5 \pm 1.4$ days (mean $\pm \mathrm{SD}, N=29$, median $=16 \mathrm{~d}$ ), and the nestling period was $16.8 \pm 1.8$ days $(N=21$, median $=16 \mathrm{~d})$. At least one egg hatched in 72 nests $(65 \%)$, and at least one nestling fledged from 31 nests $(28 \%)$. 
Fig. 1. (a) Mean precipitation ( $\mathrm{mm}$ ) per month for the three years of study (different line shapes). For each day, a mean precipitation was calculated from the 15 days before and after this date. (b) Breeding seasons (different line shapes) and incubating Little Vermilion Flycatcher (Pyrocephalus nanus) nests per month $(N=154$ nests $)$.
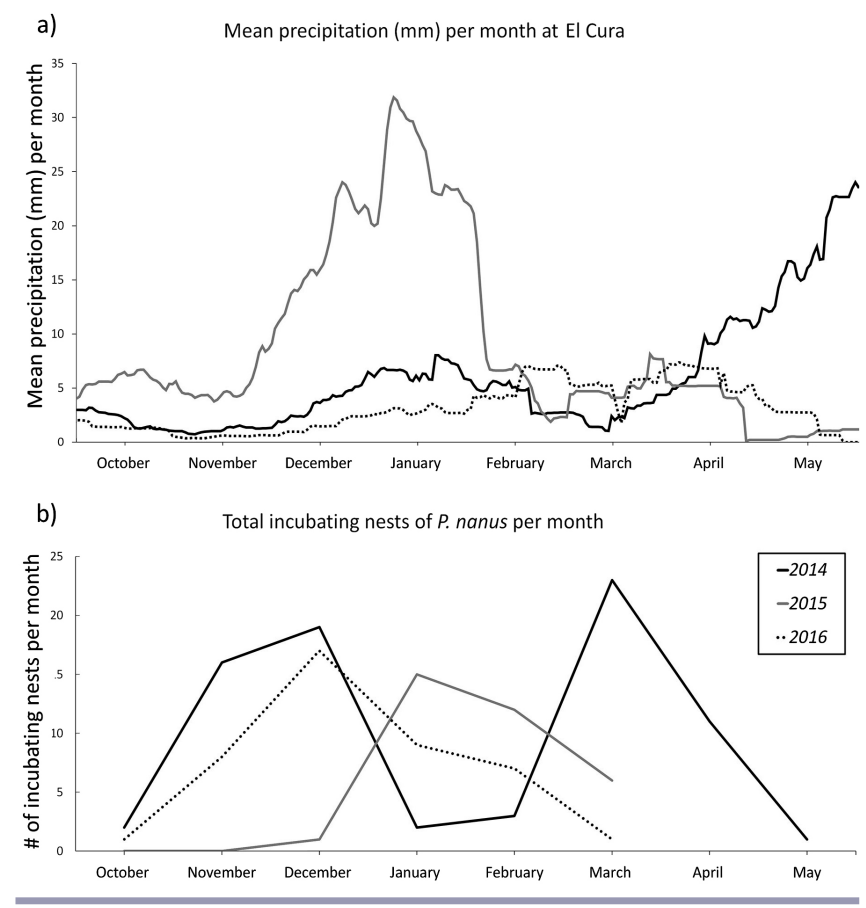

Causes of breeding failure did not differ among years $\left(\chi^{2}=5.6\right.$, $P=0.84, N=79)$. The three most frequent causes of nest failure were abandonment during incubation $(28 \%)$, dead nestlings $(25 \%)$, and empty during the nestling stage $(20 \%)$. Eight percent of nests had clear signs of nest predation (Fig. 2).

Fig. 2. Percentage of fledging success and breeding outcomes of nests of Little Vermilion Flycatchers (Pyrocephalus nanus) over three breeding seasons. Number of nests is provided above the bars $(N=110)$.

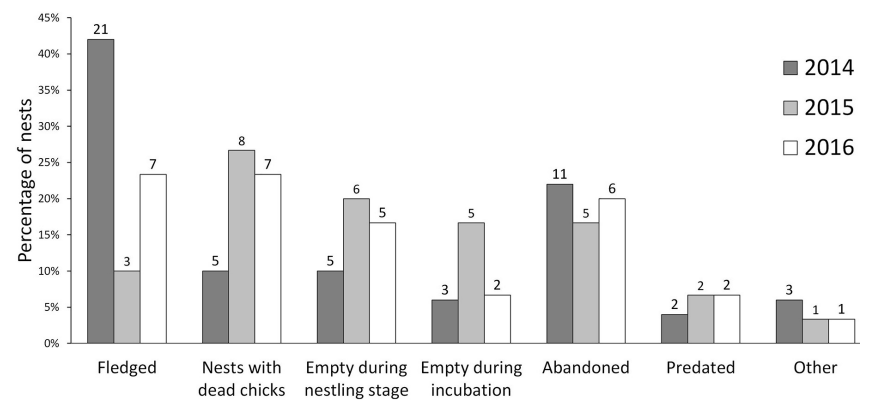

\section{Nest survival}

The best model predicting daily nest survival rate included first day of incubation (day of season), nest age, year, and total amount of rain as predictors (Table 1, Fig. 1a). Daily survival rate (DSR) declined during the breeding season (Table 2, Fig. 3a) and with nest age (Fig. 3b). The amount of rain showed a quadratic relationship to DSR, with higher nest survival at medium values (Fig. 3c). Habitat variables had no significant influence on DSR. Nest survival was significantly higher in 2014 than 2015.

Table 2. Beta estimates with standard errors and CIs of the best fitting model for nest survival of Little Vermilion Flycatchers (Pyrocephalus nanus; $N=84$ nests in 2014, 2015, and 2016).

\begin{tabular}{lccc}
\hline \hline Variable & Beta & Standard error & $\begin{array}{c}95 \% \text { Confidence } \\
\text { interval }\end{array}$ \\
\hline (Intercept $\dagger$ ) & 5.160 & 0.754 & 3.65 to $6.60^{\ddagger}$ \\
Day of season & -0.024 & 0.004 & -0.04 to $-0.159^{\ddagger}$ \\
Age of nest & -0.012 & 0.018 & -0.15 to $-0.08^{\ddagger}$ \\
2015 & -1.44 & 0.487 & -2.40 to $-0.49^{\star}$ \\
2016 & -0.623 & 0.046 & -1.52 to 0.28 \\
Total rain & 0.033 & 0.009 & 0.016 to $0.005^{\ddagger}$ \\
(Total rain) & -0.00008 & 0.00003 & -0.00005 to \\
& & $-0.00003^{\star}$ \\
\hline${ }^{\dagger}$ The table is analogous to an ANOVA and the intercept represents the \\
value for the missing level of year. \\
${ }^{\ddagger}$ Coefficients different from zero. \\
\end{tabular}

\section{Philornis prevalence and intensity}

Parasites were present in $64 \%(N=80$ nests $)$ of the monitored nests. Nests infected with $P$. downsi contained an average number of $12.6 \pm 10.3$ parasites (mean $\pm \mathrm{SD}, N=51$ ). In the nests that were abandoned during incubation $(N=19)$, parasite prevalence was $68 \%$, with an average of $9.4 \pm 5.4$ parasites $(N=13)$.

Prevalence for successful nests was lower $(40 \%, N=15)$ compared to nests that failed during nestling stage $(67 \%, N=31$, nests with dead nestlings, nestlings disappeared during feeding, and predated nests combined); we found only a trend when we tried to predict breeding success by prevalence (GLM, binomial, beta $=-1.15, \mathrm{SE}=0.65, z=-1.76, P=0.08)$. Intensity of infestation did not differ between successful and failed nests ( $P$. downsi in successful nests: $13.2 \pm 16.6$ parasites, $N=6$; failed nests: 15.6 \pm 10.8 parasites, $N=21$ ), and it was not possible to predict breeding success by parasite intensity (GLM, binomial, beta $=-1.17, \mathrm{SE}=0.42, t=-0.42, P=0.65)$.

Philornis downsi prevalence and intensity increased significantly with temperature (prevalence: logistic regression, beta $=1.26, \mathrm{SE}$ $=0.37, z=3.4, P=0.0006$; intensity: GLM, quasipoisson, beta $=0.79, \mathrm{SE}=0.18, t=4.5, P=0.0008)$. For all three years, $P$. downsi prevalence and intensity increased with date of incubation start (prevalence: logistic regression, beta $=0.03, S E=0.01, z=$ 4.1, $P=0.0004$; intensity: GLM, quasipoisson, beta $=0.01, S E$ $=0.003, t=3.2, P=0.002$ ).

\section{Parasite reduction experiment in the Little Vermilion Flycatcher}

Injection of the insecticide PermaCap CS resulted in a significant reduction of $P$. downsi in nests, with an average of $1.8 \pm 0.5$ larvae in treated nests $(N=22)$ compared to $11.9 \pm 9.6$ in untreated nests ( $N=27$; Wilcoxon test, $W=523.5, P<0.001$, Fig. 4b). Nestling success was significantly higher in treated nests; 12 of 22 treated nests had fledglings whereas no chick fledged in any of the 27 
untreated nests (Fisher's exact test, $P<0.001$, Fig. 4a). From the 10 treated but unsuccessful nests, one had dead chicks, two were found empty during the nestling stage, five were abandoned during incubation, and two failed for other reasons.

Fig. 3. Relationship between daily survival rate (plus-minus 95\% CI) and three predictors in the best fitting model including (a) Day of the season: amount of total rain is set to $80 \mathrm{~mm}$ (median) and age of nest is set to 31 days; (b) Age of nests: day of the season is 90 and amount of rain is $80 \mathrm{~mm}$; and (c) Total rain during the nesting period: day of the season is set to 90 and age of nests is 25 . In all three predictions, year was set to 2014.
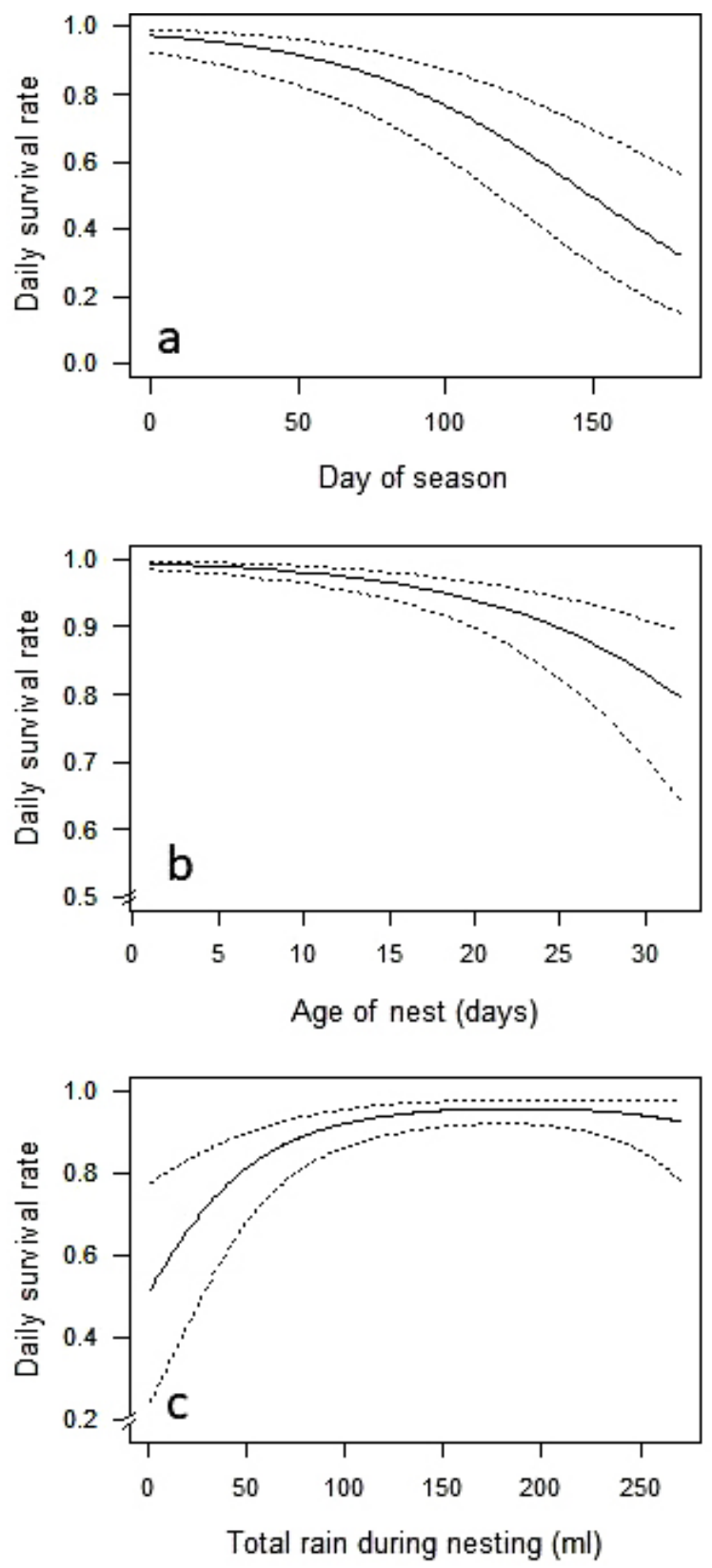

Fig. 4. (a) Breeding success in $\%$ for treated (reduced) and untreated (parasitized) Little Vermilion Flycatcher (Pyrocephalus nanus) nests. (b) Philornis downsi intensity in nests that were treated (reduced) and nests that were not treated (parasitized).
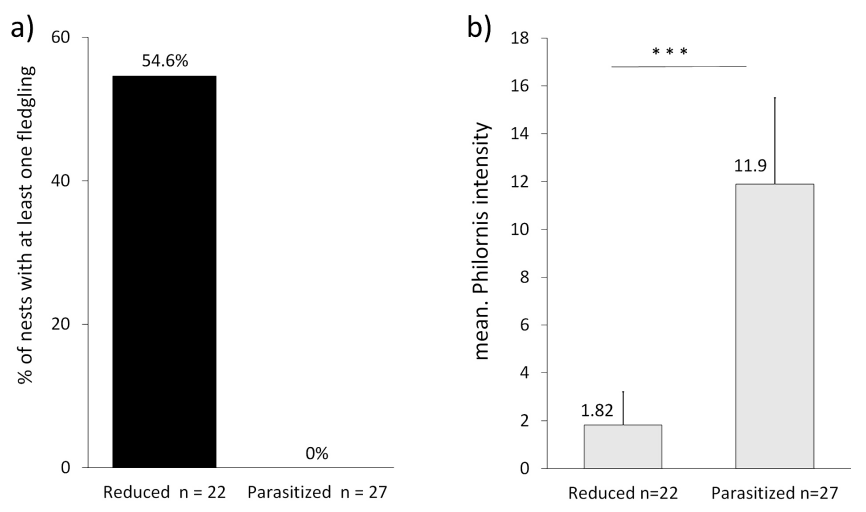

\section{DISCUSSION}

The experimental manipulation of Philornis parasitism provides strong evidence that the presence of Philornis downsi is a major contributor to the low nest success of Little Vermilion Flycatchers and has likely contributed to the rapid decline in their population. Nest success increased for nests treated with PermaCap CS, whereas all untreated (control) nests failed. We did not conduct a proper sham control (e.g., injecting water) because the injection method held the small risk of damaging the nest, which we wanted to keep to a minimum. We compared the nest height of treated and untreated nests and found no significant difference. Nevertheless, some other, inconceivable factor could have differed between experimentally treated and control nests.

The results based on natural infections (using the complete data set from untreated nest over three years) only revealed a trend when we tried to predict breeding success by $P$. downsi prevalence. One possible explanation for why breeding success was not influenced by prevalence is that the intensity of $P$. downsi larvae varies in infested nests, and studies of Darwin's finches showed that low levels of $P$. downsi prevalence and intensity can be tolerated by some species (Heimpel et al. 2017, Cimadom et al. 2019). In addition, given the low number of successful nests, it is possible that we did not have the statistical power to detect the detrimental effect of Philornis prevalence in this model. Because parasite intensity increases with nest age, surviving nests tend to have more larvae (Cimadom et al. 2014), and this positive correlation conceals the extreme detrimental effect of $P$. downsi on nest survival of younger nestlings (see as well Arendt 1985a).

Nest survival of Little Vermilion Flycatchers was also influenced by the date of incubation start, nest age, and rainfall, whereas none of the measured habitat parameters played a major role. Nests initiated earlier in the breeding season had higher nest survival, and all nests initiated after the end of January failed during all years of our study. The date of incubation start was highly correlated with rainfall and temperature. Consequently, we 
are unable to disentangle the influence of climatic parameters and the date of incubation start on the nest survival of Little Vermilion Flycatchers. Timing of the breeding season is a function of the climatic parameters, which could affect nestling success in various ways. Temperature and rainfall affect food availability, but we would expect insect availability to increase with the start of the wet and warmer climate because insect abundance starts to increase $\sim 10$ days after the first rains (Grant and Grant 1989). Our analysis reveals that nest survival depended strongly on rainfall. Nest survival decreased when rainfall was very low $(<$ $1.3 \mathrm{~mm}$ per day) and also when it rained a lot ( $>7.8 \mathrm{~mm}$ per day). Low levels of rainfall could have negative effects on food availability, and very high levels of rainfall affect parental provision rates or the ability of adults to keep nestlings warm (Cimadom et al. 2014).

However, season and climatic parameters (temperature and rainfall) could also influence the prevalence and intensity of $P$. downsi and could be an additional explanation for the relationship between these parameters and nestling success. We found that $P$. downsi prevalence and intensity increased with increasing temperature. At the cooler highland site on Santa Cruz, where mean daily temperatures were below $\sim 19-21{ }^{\circ} \mathrm{C}$ from AugustNovember (Causton et al. 2019), capture rates of $P$. downsi were significantly lower than in the warmer lowland (Causton et al. 2019). The mean temperature (2015 field season) at our study site early in the season was $17.7^{\circ} \mathrm{C}$ during the day and $16.1{ }^{\circ} \mathrm{C}$ during the night and could have been one of the possible limiting factors for $P$. downsi activity and/or its reproduction because flight activity of insects is well known to be affected by meteorological conditions, particularly ambient temperature (e.g., Taylor 1963, Berry et al. 1986, Grüebler et al. 2008).

In sum, parasite prevalence and intensity increased as the breeding season progressed, which could be a reason for the low nestling success later in the breeding season. This is the first study to find a marked variation in $P$. downsi parasitism within a breeding season in the Galápagos Islands, a pattern that has already been found in other Philornis species (Arendt 1985b). In comparable studies on Darwin's finches, $P$. downsi intensity was already high at the start of the breeding season and remained more or less stable over the breeding period (reviewed in Fessl et al. 2018). However, these studies were conducted in study areas located from 0-600 m elevation. Our study site was located higher, at 550-1000 $\mathrm{m}$ elevation, where climatic conditions, especially temperature, differ. The climatic requirements of $P$. downsi are unknown, but the absence of $P$. downsi larvae early in the breeding season suggests that conditions are not favorable for this fly to occur and/ or reproduce. Trapping data would be needed to determine if flies are only present in low numbers or do not reproduce. To date, there is no evidence for seasonal migration in P. downsi, but there are observations of single individuals moving across $600 \mathrm{~m}$ of lava tracts (F. Cunninghame, personal communication) and genetic evidence for movement between islands (Koop et al. 2021). Thus, it is possible that adult flies may migrate to higher elevations with the onset of warmer temperatures.

Furthermore, the breeding activity of Little Vermilion Flycatchers starts earlier compared to Darwin's Tree Finches, which usually starts in January and lasts until April and coincides with the rainy season (O'Connor et al. 2010, Cimadom et al. 2014).
The breeding phenology also differed among the three monitored breeding seasons. Although rainfall correlated positively with the date of incubation start, visual inspection of the graph shows that, at least in 2014, the early breeding peak was not triggered by rain. However, mist could be a sufficient source of humidity to influence the factors that trigger the start of incubation (e.g., insect abundance). More detailed studies are needed to reveal the factors driving the breeding activity of Little Vermilion Flycatchers.

Our data indicate that Little Vermilion Flycatchers are more strongly affected by $P$. downsi parasitism than Warbler Finches that are similar in size, feeding ecology, and clutch size (Cimadom et al. 2014, 2019). One factor influencing vulnerability is the age of the nestlings when nests are infested (Arendt 1985a). Several studies have indicated that, on the Galápagos Islands, $P$. downsi is gradually shifting its reproductive behavior and laying its eggs in nests earlier. Previously, larvae were found only in nests with nestlings, but, since 2012, larvae have also been recorded in nests with eggs where they feed on incubating females (Cimadom et al. 2016, Common et al. 2020). The presence of larvae early in the nesting stage leads to a further reduction in nesting success of Darwin's finches because newly hatched nestlings are being attacked by larger second and third instar larvae (Cimadom et al. 2014, Kleindorfer et al. 2014). We found that $28 \%$ of Little Vermilion Flycatcher nests were abandoned during incubation, which is similar to numbers reported for Small Tree-Finches (25\%) and Warbler Finches (28\%) on Santa Cruz Island (Cimadom et al. 2014). About 70\% of abandoned Little Vermilion Flycatcher nests were infested by $P$. downsi, with a mean of nine larvae per nest, which is a higher prevalence and intensity than in Darwin's Tree Finches on Santa Cruz Island (Cimadom et al. 2016). Philornis downsi larvae attacking incubating females could result in nest abandonment or reduced time spent incubating eggs (Oppliger et al. 1994). Reduced incubation time can cause eggs to overheat, prolongated embryo development, embryo death, and increased depredation (Fessl et al. 2018). Hence, the observed high rate of nest abandonment in the Little Vermilion Flycatcher could be a direct consequence of $P$. downsi infestation.

Clearly identifiable nest predation by rodents and owls played a minor role in nest failure for Little Vermilion Flycatchers. The value is probably higher, because some nests that were found empty during incubation and empty during nestling phase may also have been depredated. Predation reported for several Darwin's finches in the highlands of Santa Cruz Island was highly variable, from $9-22 \%$ in one study (Cimadom et al. 2014) to $23-$ $67 \%$ in another study (Dudaniec et al. 2007).

Site fidelity between seasons was low, with only $20 \%$ and $6 \%$ of marked adults resighted in the same territory in the following seasons. This could point either toward low year-to-year survival or low site fidelity between years. Systematic banding to determine adult and juvenile movements and regular population censuses would help to increase the knowledge and understanding of the population dynamics of Little Vermilion Flycatchers. Population models that take into account existing threats such as $P$. downsi, predation, and increased frequency of extreme weather events such as El Niño and La Niña might help to predict population trajectories and target protection measures to prevent the extinction of Little Vermilion Flycatchers on other islands. 


\section{CONCLUSION}

Our results provide clear evidence that $P$. downsi parasitism is the main cause of nest failure for Little Vermilion Flycatchers because nests were only successful during months with low levels of $P$. downsi parasitism. Our results and those of Leuba et al. (2020) suggest that successful reproduction is restricted to higher altitudes where low temperature and a number of potential factors yet to be studied limit $P$. downsi parasitism at least at the onset of the breeding season. Injecting an insecticide is an efficient method for limiting the effects of the invasive parasite but is labor intensive and restricted by nest height. Self-fumigation is a promising alternative to injection. This method relies on birds taking material treated with an insecticide back to the nest (Knutie at al. 2014). Preliminary experiments with feather dispensers near nests of Little Vermilion Flycatchers show promising results (D. Anchundia, unpublished data). In addition, research has shown that invasive plants reduce hunting abilities and food quality, which in turn impacts egg laying, incubation success, and resistance to $P$. downsi (Cimadom et al. 2019, Leuba et al. 2020). Thus, a holistic management strategy is needed that includes the development and implementation of stopgap measures and longterm solutions such as biological control to reduce mortality by P. downsi, habitat restoration to improve prey abundance and prey access for insectivorous birds, and control of introduced predators (rodents, cats, and smooth-billed ani [Crotophaga ani]) to ensure maximal reproductive success. The implementation of such management plans will be crucial to safeguard threatened bird populations in the Galápagos Islands including the Little Vermilion Flycatcher.

Responses to this article can be read online at: https://www.ace-eco.org/issues/responses.php/2040

\section{Acknowledgments:}

This study was part of the Galápagos Landbird Conservation Plan, implemented jointly by the Charles Darwin Foundation and the Galápagos National Park Directorate under the Philornis downsi umbrella project led by Charlotte Causton. This work would have been impossible without the help of the team of volunteers of the Charles Darwin Foundation. Special thanks to Patricio Herrera, Wilson Iñiguez, Luis Cevallos, Lucy Haskell, Maria de los Angeles Pastuzo, and Ximena Calderón. We thank Oscar Carvajal and Gabriela Yépez from the Galápagos National Park for their logistic support and the National Park rangers from Isabela Island for their enthusiastic participation when it was asked. We thank Arno Cimadom for statistical advice, Caroline Raby and Courtney Pike for editing English, W. Arendt for his detailed comments on a former draft, and anonymous referees for their helpful corrections and suggestions. This publication is contribution number 2247 of the Charles Darwin Foundation for the Galápagos Islands. Our study was conducted in the protected areas of the Galápagos National Park. Permission to conduct this study was granted by the Galápagos National Park (Permit numbers: PC-66-14, PC-09-15, PC-33-16, PC-07-17, and PC-01-18). Experimental protocols were approved by the Charles Darwin Research Station. All methods were carried out in accordance with the approved guidelines. Funding was provided by Galápagos Conservancy; International Community Foundation with a grant awarded by The Leona M. and Harry B. Helmsley Charitable Trust; Lindblad Expeditions NationalGeographic; Swiss Association of Friends of the Galápagos Islands with a grant awarded by Temperatio. S.T. was funded by the FWF, project number P 26556-B22.

\section{LITERATURE CITED}

Akaike, H. 1973. Information theory and an extension of the maximum likelihood principle. Pages 267-281 in B. N. Petrov and F. Csáki, F. editors. Proceedings of the 2nd International Symposium on Information Theory. Akadémiai Kiadó, Budapest, Hungary.

Arendt, W. 1985a. Philornis ectoparasitism of Pearly-eyed Thrashers. I. Impact on growth and development of nestlings. Auk 102:270-280. /https://doi.org/10.2307/4086769

Arendt, W. 1985b. Philornis ectoparasitism of Pearly-eyed Thrashers. II. Effects on adults and reproduction. Auk 102:281-292. https://doi.org/10.2307/4086770

Berry, I. L., A. K. Nelson, and A. B. Broce. 1986. Effects of weather on capture of stable flies (Diptera: Muscidae) by alsynite fiber glass traps. Environmental Entomology 15:706-709. https:// doi.org/10.1093/ee/15.3.706

Birdlife International. 2017. Pyrocephalus nanus (amended version of 2016 assessment). The IUCN Red List of threatened species: e.T103682926A119555197. https://dx.doi.org/10.2305/ IUCN.UK.2017-3.RLTS.T103682926A119555197.en

Blackburn, T. M., P. Cassey, R. P. Duncan, K. L. Evans, and K. J. Gaston. 2004. Avian extinction and mammalian introductions on oceanic islands. Science 305:1955-1958. https://doi. org/10.1126/science. 1101617

Burnham, K. P., and D. R. Anderson. 2002. Model selection and multimodel inference: a practical and information-theoretic approach. Springer, New York, New York, USA.

Carmi, O., C. C. Witt, A. Jaramillo, and J. P. Dumbacher. 2016. Phylogeography of the Vermilion Flycatcher species complex: multiple speciation events, shifts in migratory behavior, and an apparent extinction of a Galápagos-endemic bird species. Molecular Phylogenetics and Evolution 102:152-173. https://doi. org/10.1016/j.ympev.2016.05.029

Causton, C. E., R. D. Moon, A. Cimadom, R. A. Boulton, D. Cedeño, M. P. Lincango, S. Tebbich, and A. Ulloa. 2019. Population dynamics of an invasive bird parasite, Philornis downsi (Diptera: Muscidae), in the Galapagos Islands. PLoS ONE 14: e0224125. https://doi.org/10.1371/journal.pone.0224125

Causton, C. E., S. B. Peck, B. J. Sinclair, L. Roque-Albedo, C. J. Hodgson, and B. Landry 2006. Alien insects: threats and implications for the conservation of the Galápagos Islands. Annals of the Entomological Society of America 99:121-143. https://doi.org/10.1603/0013-8746(2006)099[0121:AITAIF]2.0.CO;2 
Cimadom, A., C. Causton, D. H. Cha, D. Damiens, B. Fessl, R. Hood-Nowotny, P. Lincango, A. E. Mieles, E. Nemeth, E. M. Semler, S. A. Teale, and S. Tebbich. 2016. Darwin's finches treat their feathers with a natural repellent. Scientific Reports 6:34559. https://doi.org/10.1038/srep34559

Cimadom, A., H. Jäger, C. H. Schulze, R. Hood-Nowotny, C. Wappl, and S. Tebbich. 2019. Weed management increases the detrimental effect of an invasive parasite on arboreal Darwin's finches. Biological Conservation 233:93-101. https://doi. org/10.1016/j.biocon.2019.02.025

Cimadom, A., A. Ulloa, P. Meidl, M. Zöttl, E. Zöttl, B. Fessl, E. Nemeth, M. Dvorak, F. Cunninghame, and S. Tebbich. 2014. Invasive parasites, habitat change and heavy rainfall reduce breeding success in Darwin's Finches. PLoS ONE 9:e107518. https://doi.org/10.1371/journal.pone.0107518

Common, L. K., J. A. O’Connor, R. Y. Dudaniec, K. J. Peters, and S. Kleindorfer. 2020. Evidence for rapid downward fecundity selection in an ectoparasite (Philornis downsi) with earlier host mortality in Darwin's finches. Journal of Evolutionary Biology 33:524-533. https://doi.org/10.1111/jeb.13588

Cronk, Q. C. B., and J. L. Fuller 1995. Plant invaders: the threat to natural ecosystems. Chapman and Hall, London, UK.

Dinsmore, S. J., and J. J. Dinsmore. 2007. Modeling avian nest survival in program MARK. Studies in Avian Biology 34:73-83. [online] URL: https://lib.dr.iastate.edu/nrem_pubs/88

Dudaniec, R. Y., B. Fessl, and S. Kleindorfer. 2007. Interannual and interspecific variation in intensity of the parasitic fly, Philornis downsi, in Darwin's finches. Biological Conservation 139:325-332. https://doi.org/10.1016/j.biocon.2007.07.006

Dvorak, M., B. Fessl, E. Nemeth, D. Anchundia, J. Cotín, C. H. Schulze, W. Tapia, and B. Wendelin. 2020. Survival and extinction of breeding landbirds on San Cristóbal, a highly degraded island in the Galápagos. Bird Conservation International 30:381-395. https://doi.org/10.1017/S0959270919000285

Dvorak, M., B. Fessl, E. Nemeth, S. Kleindorfer, and S. Tebbich. 2012. Distribution and abundance of Darwin's finches and other land birds on Santa Cruz Island, Galápagos: evidence for declining populations. Oryx 46:78-86. https://doi.org/doi:10.1017/ S0030605311000597

Dvorak, M., E. Nemeth, B. Wendelin, P. Herrera, D. Mosquera, D. Anchundia, C. Sevilla, S. Tebbich, and B. Fessl. 2017. Conservation status of landbirds on Floreana: the smallest inhabited Galápagos Islands. Journal of Field Ornithology 88:132-145. https://doi.org/10.1111/jofo.12197

Fessl, B., D. Anchundia, J. Carrión, A. Cimadom, J. Cotin, F. Cunninghame, M. Dvorak, D. Mosquera, E. Nemeth, C. Sevilla, S. Tebbich, B. Wendelin, and C. Causton. 2017. Galapagos landbirds (passerines, cuckoos and doves): status, threats and knowledge gaps. Pages 149-160 in Galapagos National Park Directorate, Governing Council of Galapagos, Charles Darwin Foundation, and Galapagos Conservancy, editors. Galapagos report 2015-2016. Puerto Ayora, Galapagos, Ecuador. [online] URL: https://www.galapagos.org/wp-content/uploads/2017/12/5GR-2015-16-Biodiversity-and-Ecosystem-Restoration-section.pdf
Fessl, B., G. E. Heimpel, and C. E. Causton. 2018. Invasion of an avian nest parasite, Philornis downsi, to the Galapagos Islands: colonization history, adaptations to novel ecosystems, and conservation challenges. Pages 213-257 in P. G. Parker, editor. Disease ecology: Galapagos birds and their parasites. Springer Nature, Cham, Switzerland.

Fessl, B., S. Kleindorfer, and S. Tebbich. 2006b. An experimental study on the effects of an introduced parasite in Darwin's finches. Biological Conservation 127:55-61. https://doi.org/10.1016/j. biocon.2005.07.013

Fessl, B., B. J. Sinclair, and S. Kleindorfer. 2006a. The life cycle of Philornis downsi (Diptera: Muscidae) parasitizing Darwin's finches and its impacts on nestling survival. Parasitology 133:739-747. https://doi.org/10.1017/s0031182006001089

Fessl, B., and S. Tebbich. 2002. Philornis downsi-a recently discovered parasite on the Galápagos archipelago - a threat for Darwin's finches? Ibis 144:445-451. https://doi.org/10.1046/ j.1474-919X.2002.00076.x

Fessl, B., G. H. Young, R. P. Young, J. Rodríguez-Matamoros, M. Dvorak, S. Tebbich, and J. E. Fa. 2010. How to save the rarest Darwin's finch from extinction: the mangrove finch on Isabela Island. Philosophical Transactions of the Royal Society B: Biological Sciences 365:1019-1030. https://doi.org/10.1098/ rstb.2009.0288

Grant, B. R., and P. R. Grant. 1989. Evolutionary dynamics of a natural population. The large cactus finch of the Galapagos. University of Chicago Press, Chicago, Illinois, USA.

Grant, P. R., B. R. Grant, K. Petren, and L. F. Keller. 2005. Extinction behind our backs: the possible fate of one of the Darwin's finch species on Isla Floreana, Galápagos. Biological Conservation 122:499-503. https://doi.org/10.1016/j.biocon.2004.09.001

Grüebler, M. U., M. Morand, and B. Naef-Daenzer. 2008. A predictive model of the density of airborne insects in agricultural environments. Agriculture, Ecosystems \& Environment 123:75-80. https://doi.org/10.1016/j.agee.2007.05.001

Harris, M. P. 1974. A field guide to the birds of Galapagos. Collins, London, UK.

Heimpel, G. E., A. Hillstrom, D. Freund, S. A. Knutie, and D. H. Clayton. 2017. Invasive parasites and the fate of Darwin's finches in the Galapagos Islands: the case of the Vegetarian Finch (Platyspiza conirostris). Wilson Journal of Ornithology 129:345-349. https://doi.org/10.1676/16-050.1

Jiménez-Uzcátegui, G., D. Wiedenfeld, C. A. Valle, H. Vargas, P. Piedrahita, L. Muñoz-Abril, and J. J. Alava. 2019. Threats and vision for the conservation of Galápagos birds. Open Ornithology Journal 12:1-15. https://doi.org/10.2174/1874453201912010001

Kleindorfer, S., and R. Y. Dudaniec. 2016. Host-parasite ecology, behavior and genetics: a review of the introduced fly parasite Philornis downsi and its Darwin's finch hosts. BMC Zoology 1:1-19. https://doi.org/10.1186/s40850-016-0003-9

Kleindorfer, S., K. J. Peters, G. Custance, R. Y. Dudaniec, and J. A. O'Connor. 2014. Changes in Philornis infestation behavior threaten Darwin's finch survival. Current Zoology 60:542-550. https://doi.org/10.1093/czoolo/60.4.542 
Knutie, S. A., S. M. McNew, A. W. Bartlow, D. A. Varas, and D. H. Clayton. 2014. Darwin's finches combat introduced nest parasites with fumigated cotton. Current Biology 24:R355-R356. https://doi.org/10.1016/j.cub.2014.03.058

Koop, J. A. H., C. E. Causton, M. Bulgarella, E. Cooper, and G. E. Heimpel. 2021. Population structure of a nest parasite of Darwin's finches within its native and invasive ranges. Conservation Genetics 22:11-22. https://doi.org/10.1007/ s10592-020-01315-0

Koop, J. A. H., J. P. Owen, S. A. Knutie, M. A. Aguilar, and D. H. Clayton. 2013. Experimental demonstration of a parasiteinduced immune response in wild birds: Darwin's finches and introduced nest flies. Ecology and Evolution 3:2514-2523. https:// doi.org/10.1002/ece3.651

Laake, J. 2013. RMark: an R interface for analysis of capturerecapture data with MARK. AFSC Processed Report 2013-01, Alaska Fisheries Science Center, National Oceanic and Atmospheric Administration, National Marine Fisheries Service, Seattle, Washington, USA. [online] URL: https://repository. library.noaa.gov/view/noaa/4372/noaa_4372_DS1.pdf

Leuba, C., S. Tebbich, E. Nemeth, D. Anchundia, E. Heyer, D. A. Mosquera, H. Richner, M. L. Rojas Allieri, C. Sevilla, and B. Fessl. 2020. Effect of an introduced parasite in natural and anthropogenic habitats on the breeding success of the endemic little vermilion flycatcher Pyrocephalus nanus in the Galápagos. Journal of Avian Biology 51:e02438. https://doi.org/10.1111/ jav. 02438

McNew, S. M., and D. H. Clayton. 2018. Alien invasion: biology of Philornis flies highlighting Philornis downsi, an introduced parasite of Galápagos birds. Annual Review of Entomology 63:369-387. https://doi.org/10.1146/annurev-ento-020117-043103

Merlen, G. 2013. Gone, gone...going: the fate of the vermilion flycatcher on Darwin's Islands. Pages 180-188 in Galapagos National Park Directorate, Governing Council of Galapagos, Charles Darwin Foundation, and Galapagos Conservancy, editors. Galapagos report 2011-2012. Puerto Ayora, Galapagos, Ecuador. [online] URL: https://www.galapagos.org/wp-content/ uploads/2019/09/25.-BIODIV-vermillion-flycatcher.merlen.pdf

O’Connor, J. A., F. J. Sulloway, J. Robertson, and S. Kleindorfer. 2010. Philornis downsi parasitism is the primary cause of nestling mortality in the critically endangered Darwin's medium tree finch (Camarhynchus pauper). Biodiversity and Conservation 19:853-866. https://doi.org/10.1007/s10531-009-9740-1

Oppliger, A., H. Richner, and P. Christe. 1994. Effect of an ectoparasite on lay date, nest-site choice, desertion, and hatching success in the great tit (Parus major). Behavioral Ecology 5:130-134. https://doi.org/10.1093/beheco/5.2.130
R Core Team. 2017/2018. R: A language and environment for statistical computing. R Foundation for Statistical Computing. Vienna, Austria.

Steadman, D. W. 1995. Prehistoric extinctions of Pacific Island birds: biodiversity meets zooarchaeology. Science 267:1123-1131. https://doi.org/10.1126/science.267.5201.1123

Steadman, D. W. 2006. Extinction and biogeography of tropical Pacific birds. University of Chicago Press, Chicago, Illinois, USA.

Taylor, L. R. 1963. Analysis of the effect of temperature on insects in flight. Journal of Animal Ecology 32:99-117. https://doi. org/10.2307/2520

White, G. C., and K. P. Burnham. 1999. Program MARK: survival estimation from population of marked animals. Bird Study 46: S120-S138. https://doi.org/10.1080/00063659909477239
Editor-in-Chief: Alexander L.Bond Subject Editor: Nicholas JBayly
Sponsored by the Society of Canadian Ornithologists and Birds Canada

Parrainée par la Société des ornithologistes du Canada et Oiseaux Canada

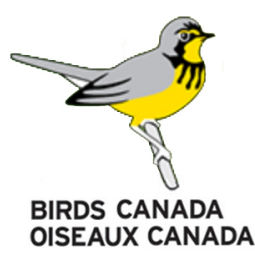




\section{Appendix 1}
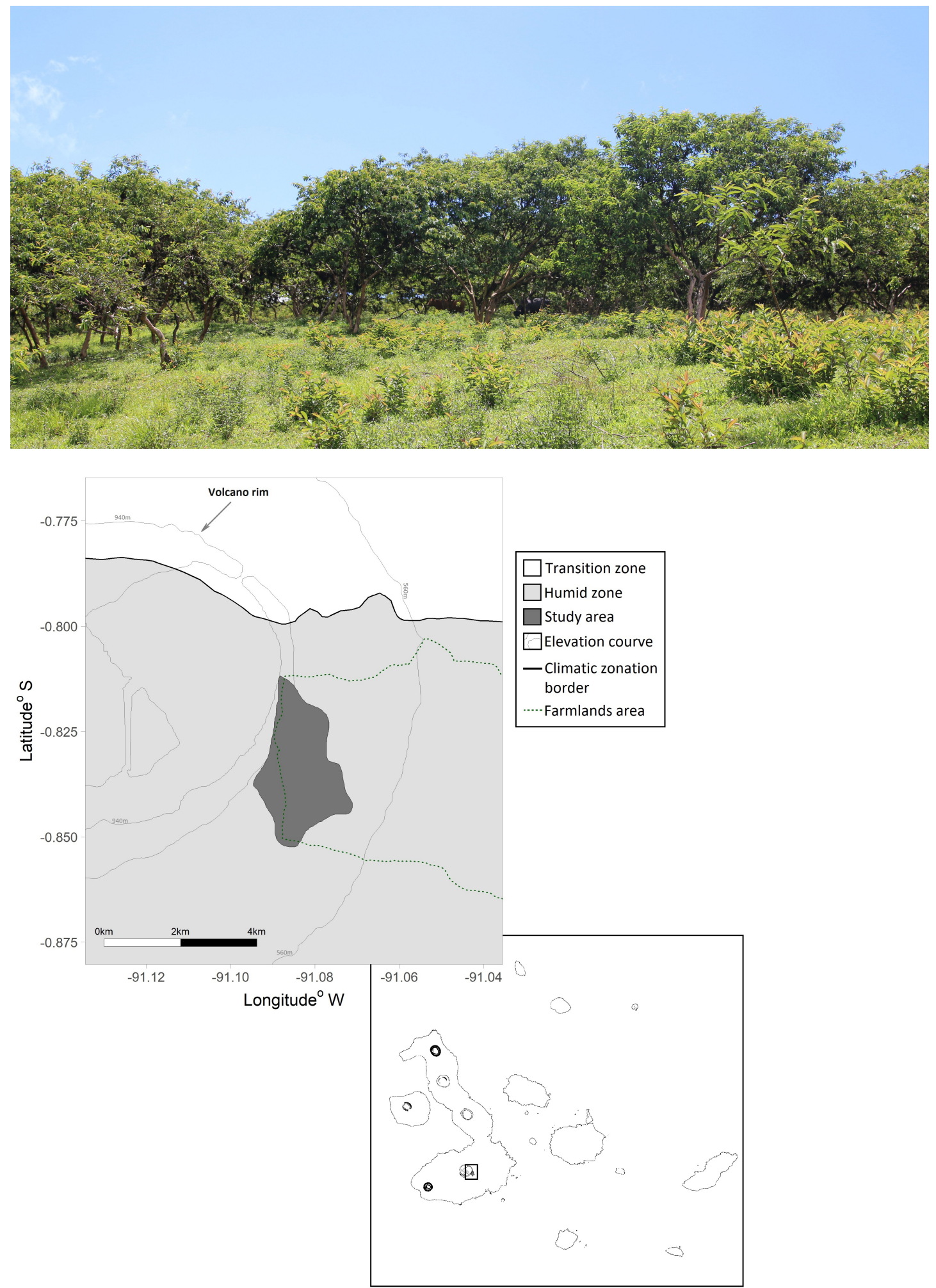

Fig. A1.1. The study area El Cura is found in the humid zone of Isabela Island (square on Galápagos map), close to the volcano rim of Sierra Negra and lies predominately in the agricultural zone. The photo shows a typical vegetation consisting of 2 to $5 \mathrm{~m}$ high guava trees (Psidium guajava) surrounded by pasture land. Photo: Celina Leuba, CDF. 
Appendix 2

Table A2.1. Comparing Model selection results for the best model either with day of season or Philornis intensity or prevalence. Daily nest survival (S) of Little Vermilion Flycatchers, calculated for 74 nests in 2014, 2015 and 2016.

\begin{tabular}{|c|c|c|c|c|c|}
\hline Model & $\mathrm{K}^{\dagger}$ & AICc & $\triangle \mathrm{AICc}$ & Weight & Deviance \\
\hline $\mathrm{S} \sim$ day of season + year + nest age + rain + rain $^{2}$ & 6 & 329.94 & 0.00 & 0.19 & 315.83 \\
\hline S Philornis Prevalence + year + nest age + rain + rain $^{2}$ & 6 & 333.43. & 3.50 & 0.034 & 319.33. \\
\hline$\sim \sim$ Philornis Intensity + year + nest age + rain + rain $^{2}$ & 6 & 334.76 & 4.84 & 0.017 & 320.67 \\
\hline
\end{tabular}

